\title{
Heavy Metal Bioaccumulation in Brown Algae Cystoseira compressa in Algerian Coasts, Mediterranean Sea
}

\author{
Redhouane Benfares ${ }^{1} \cdot$ Halima Seridi ${ }^{1}$. \\ Yasmin Belkacem ${ }^{2} \cdot$ Ahmed Inal $^{2}$
}

Received: 16 October 2014 / Accepted: 23 March 2015 /Published online: 11 April 2015

(C) Springer International Publishing Switzerland 2015

\begin{abstract}
This study was undertaken to investigate and assess trace metal $(\mathrm{Cd}, \mathrm{Pb}, \mathrm{Cr}$, and $\mathrm{Hg}$ ) concentrations in the Cystoseira compressa algae from the coastal city of Bou Ismail (Algeria). Spatial and temporal variations in the concentrations of these heavy metals were studied in the following three sampling sites: site 1 and site 2 were major wastewater discharge zones and site 3 was located close to areas with high industrial activity. Seawater, sediments and algae in the wastewater from the three sites were submitted to physico-chemical analyses to determine the concentrations of heavy metals and the level of pollution in the region. The results revealed that site 1 (designed as desalination) and site 2 (designed as industrial waste) were non-compliant, which was attributed to heavy loads of heavy metals and wastewater discharged by industrial activity and absence of regular treatment. Site 3 (designed as cove koali), on the other hand, was noted to represent a reference site. Overall, the results provided evidence for the heavy metal bioaccumulation of algae from the genus Cystoseira and their efficiency for use as biomarkers of pollution in coastal areas.
\end{abstract}

Keywords Pollution C Cystoseira compressa $\cdot$ Concentration $\cdot$ Heavy metals $\cdot$ Sediment

\section{Introduction}

There have been growing concerns worldwide over the increasing concentrations of pollutants, particularly heavy metals, in the environment, and their adverse effects on human health and safety. Heavy metals released from various industrial activities into the aquatic environment

Redhouane Benfares

red_benfares@yahoo.fr

1 Laboratory of Oceanography Biologic and Marine Environment, Faculty of Biological Sciences, University of Science and Technology of Houari Boumedien (USTHB), PO Box 32, El Alia,Bab Ezzouar, 16111 Algiers, Algeria

2 Laboratory of Aquatic Ecosystem, National Centre for Research and Development of Fisheries and Aquaculture (CNRDPA) 11, Bd Amirouche, PO Box 67, Bou Ismail 42415 Tipaza, Algeria 
could accumulate in the biota and sometimes exceed their tolerance ability, thus bringing adverse toxicological, ecological, and environmental effects (Reichelt-Brushett 2012). Monitoring the metal loads and pollution sources in aquatic environments is, therefore, critical to evaluate the impacts, and, if needed, take measures to protect the ecosystem.

Seaweeds (benthic algae) have commonly been employed as indicators of biologically available trace metals in aqueous environments (Alahverdi and Savabieasfahani 2012; Sondergaard et al. 2014). The rationale behind the use of seaweeds as biomarkers of metal contamination is reasonable for several reasons. Firstly, metal concentrations in solution are often near analytical detection limits and may be highly variable over time. Seaweeds concentrate metals from solution and integrate shortterm temporal fluctuations in concentrations. Secondly, no fully developed empirical methods are currently available for distinguishing the biologically available fraction of total dissolved metal levels in natural systems. By definition, seaweed will accumulate only those metals that are biologically available. Last but not least, since plants do not ingest particulate-bound metals (as do animals), plants should accumulate metals only from solution.

Algal populations have been extensively used as indicators of water pollution. In fact, algae play an important role in the functioning and balance of all aquatic ecosystems; they also contribute significantly to the economic activity in several countries around the world (Güner et al. 2015). The coastal city of Bou Ismaill, Tipaza, north-central Algeria is characterized by increasing industrial activity and faces serious challenges of wastewater management. The region has an important and natural deposit of seaweed. The latter can serve as bioindicator for metal pollution and provide valuable data for the health status of the inhabitants of the city of Bou Ismaill. Accordingly, the present study aimed to investigate the spatial and temporal variations in the concentrations of trace metals $(\mathrm{Cd}, \mathrm{Pb}, \mathrm{Cr}$, and $\mathrm{Hg})$ in the seawater, sediments and brown algae Cystoseira compressa from three different sites, two major wastewater discharge zones and one proximal to high industrial activity.

\section{Materials and Methods}

\subsection{Chemicals and Reagents}

Unless specified, all chemicals and reagents were of the analytical grade or highest available purity and purchased from Sigma Chemical Co. (St. Louis, MO, USA).

\subsection{The Study Sites}

Brown algae were collected from three sites (desalination and industrial waste stations) located on the coast of the Bay of Bou Ismail (Fig. 1). The sites were selected due to their richness in algal populations and proximity to zones of industrial activity. The seawater, sediments and brown algae Cystoseira compressa from the three different sites were used to evaluate the flow of effluents and their impacts on the receiving marine environment.

Sea water samples were collected in polyethylene bottles for physico-chemical analysis. Algae were collected with their bases, stored in plastic bags with seawater. Sediment samples were bored out to a stainless ugly dump in plastic bags. 


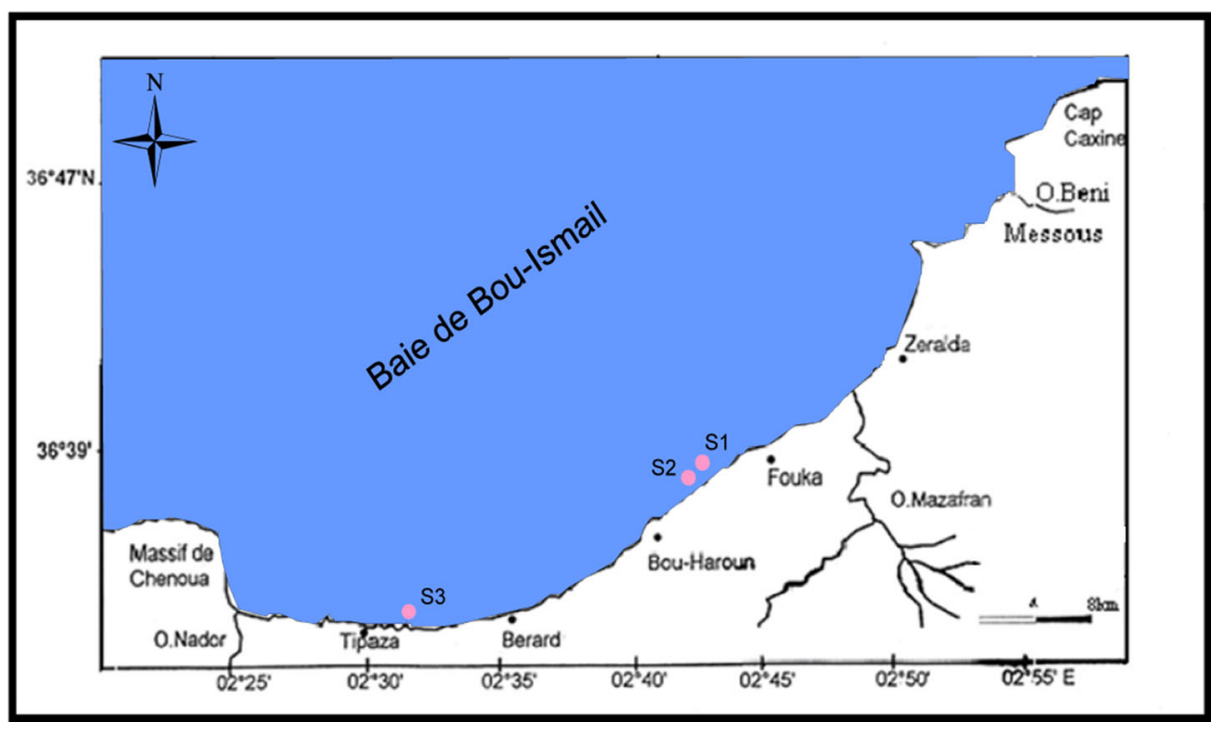

Fig. 1 Location of sampling sites algae along the coast of the Bay of Bou Ismail (Tipaza, Algeria). Site S1: Desalination, Site S2: Industrial waste of Bou Ismaill, and site S3: Cove Koali

\subsection{Physico-Chemical Analyses of Seawater}

Physico-chemical parameters analyzed have commonly been used as important markers of continental influence, particularly in cases involving mixtures of seawater with inland waters. The physico-chemical assays performed on the environment of algal species used in the present study involved the in situ measurement and analysis of temperature, $\mathrm{pH}$, salinity, dissolved oxygen (these parameters were measured by a multi-parameter YSI 556 MPS), and nutrient salts (nitrites, nitrates, ammonia nitrogen, and phosphorus) as previously described elsewhere (Boukhalfa et al. 2006; Rodier 1996).

\subsection{Sampling and Sample Preparation}

Specimens of brown algae were sampled on a seasonal basis throughout the period of the study (from February 2012 to July 2012) following a sampling protocol described (Aminot and Chaussepied 1983). The collected algal samples were cleared of their epiphytes and debris adhering to their fronds, washed up on the sea water, and then placed in plastic bags. Upon arrival at the laboratory, the algae were rinsed with double distilled water, dried at $70{ }^{\circ} \mathrm{C}$ for $48 \mathrm{~h}$, and then ground to a fine powder. The powder was then used for mineralization assays.

\subsection{Digestion or Mineralization}

\subsubsection{Pretreatment of Samples for the Analysis of Algae Mercury}

An amount of $1 \mathrm{~g}$ of each sample was transferred into a $250 \mathrm{~mL}$ Erlenmayer borosilicate flaskpreviously washed with nitric acid and ultra-pure water. Volumes of $30 \mathrm{~mL}$ of $65 \%$ nitric acid $\left(\mathrm{HNO}_{3}\right)$ and $20 \mathrm{~mL}$ of sulfuric acid $\left(\mathrm{H}_{2} \mathrm{SO}_{4}\right)$ (solution $\left.v / v\right)$ were carefully introduced to 
the flasks, respectively. The samples were left to rest for $15 \mathrm{~min}$, and then $5 \mathrm{~g}$ of powdered potassium permanganate $\left(\mathrm{KMnO}_{4}\right)$ were added to the solutions. Finally, powdered $\mathrm{KMnO}_{4}$ was then carefully added to the mixture and stirred for $15 \mathrm{~min}$. The mixtures were heated in a water bath at $95^{\circ} \mathrm{C}$ for $2 \mathrm{~h}$. During digestion, extreme care was given to prevent the excess of potassium permanganate. Powdered $\mathrm{KMnO}_{4}$ was present throughout the heating period, and the sample solution was cooled at room temperature. An amount of $5 \mathrm{~mL}$ of chloride hydroxylamine $\left(\mathrm{NH}_{2} \mathrm{OH}\right)$ solution was added to each sample solution to reduce the excess of $\mathrm{KMnO}_{4}$. The sample solutions were filtered in $250 \mathrm{~mL}$ vials using filter paper with $0.5 \mu \mathrm{m}$ porosity, washed thoroughly with dilute nitric acid, and rinsed with ultrapure water. The vials were filled with ultra-pure water (Schutze and Muller 1979; Singh et al. 2012).

\subsubsection{Sample (Seaweed) Pretreatments for the Analysis of Chromium, Lead and Cadmium}

Fractions of $1 \mathrm{~g}$ of each sample were prepared for analysis. Each of these fractions was transferred into $500 \mathrm{~mL}$ Erlenmayer borosilicate glass flasks previously washed with nitric acid and ultra pure water. Volumes of $7 \mathrm{~mL}$ of $65 \% \mathrm{HNO}_{3}$ and $21 \mathrm{~mL}$ of $37 \%$ hydrochloric acid $(\mathrm{HCl})$ were carefully introduced to the solutions. The flasks were left overnight to allow cold acid attack. The experiments then proceeded to hot acid attack, and the solution was kept below the boiling point of refrigerants to allow the resulting steam to settle and prevent losses. The samples solutions were filtered in $100 \mathrm{~mL}$ vials through filter paper with a porosity of $0.5 \mu \mathrm{m}$. The filter paper was washed to dilute nitric acid and rinsed with ultrapure water pure. The flask was filled with ultra-pure water (Escuder-Gilabert et al. 2007; ISO:9174 1998).

\subsection{Preparation of Sediment Samples}

\subsubsection{Pretreatment of Sediment Samples for Heavy Metal Analyses}

The sediment samples were carefully tacked to avoid contamination; they were kept on board (pre-freezing) in the laboratory and submitted to the treatment procedures described below.

\subsubsection{Lyophilization}

The samples were lyophilized in a Bioblock Scientific Christ ALPHA 1-2 (temperature $=-40{ }^{\circ} \mathrm{C}$ and pressure $=0.1 \mathrm{mbar}$ ) for $48 \mathrm{~h}$ using freeze drying and subsequent dehydration by sublimation.

\subsubsection{Grinding and Sieving}

The sediment was ground with the lyophilizate in porcelain mortar until fine powder was obtained. The latter was sieved in a mesh sieve and representative fractions were used for the determination of heavy metals and the affinity between those metals and fine particles.

\subsubsection{Digestion or Mineralization}

Digestion frees different metals absorbed on the surface of sediment particles by extraction and facilitates the determination of dissolved trace elements by flame atomic absorption spectroscopy. 


\subsection{Analysis by Atomic Absorption Spectroscopy (AAS)}

Atomic absorption spectroscopic analysis was performed by a Perkin Elmer Analyst 700 atomic absorption spectrometer equipped with a flame, furnace, and cold vapor system connected to the ISAF, a mechanism that allowed for the analysis of the evaporation reaction of the mixture of mercury, $\mathrm{HCl}, \mathrm{Sn}$ (II) $\mathrm{Cl}_{2}$, and the sample. The carrier gas was argon, an inert gas that does not react with the test solutions.

\subsection{Statistical Analysis}

The data represent the mean and standard deviation (mean \pm SD) for triplicate samples. They were analyzed in Microsoft Excel, and results were considered statistically significant for $\mathrm{p}$ values of less than or equal to 0.05 .

\section{Results and Discussion}

\subsection{Different Stages of Algal Growth During Sampling}

The present study focused on the brown algae Cystoseira compressa, which are seaweed with good heavy metal bioaccumulative potential. The algae were sampled three times and their three stages of development were investigated.

\subsubsection{The First Sampling Stage}

The first stage of development was characterized by a dark color, a length size ranging between 7 and $15 \mathrm{~cm}$, and dense grouped clumps (Fig. 2a).

\subsubsection{The Second Sampling Stage}

The second stage was characterized by light greenish color reflections; branches growing along can reach $30 \mathrm{~cm}$ in length, and tufts leaving more space for the development of main branches (Fig. 2b).

\subsubsection{The Third Sampling Stage}

The third stage was characterized by the onset of cyst formations (the reproductive organs in most of the brown algae), with lighter color and rounder and shorter twigs (Fig. 2c).

\subsection{Results and Discussion of Physico-Chemical Analysis Seawater}

The results of physico-chemical parameters of the seawater during the 6 months of development of the algae Cystoceira compressa, provided data on the state and quality of the marine waters, of the three selected sites in the Bay of Bou Ismail are summarized in Fig. $3 \mathrm{a}$ and $\mathrm{b}$.

Temperature values recorded during the study period were within the limits of seasonal values. The sharp increase in May was due to the seasonal warming of air 
a

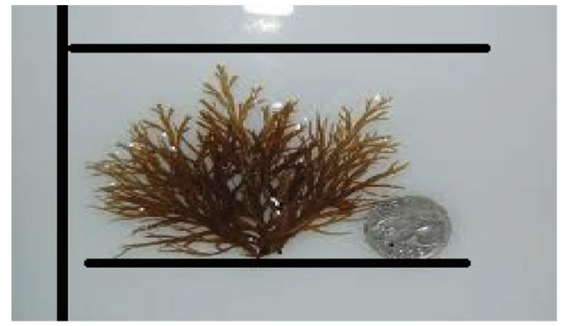

b

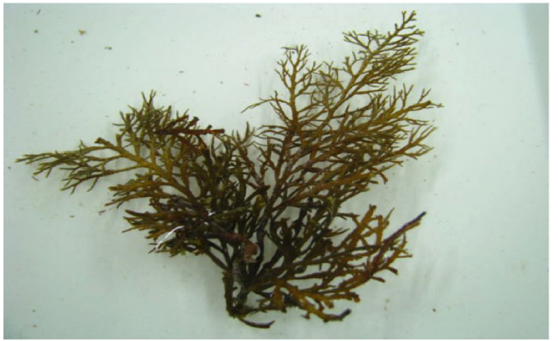

C

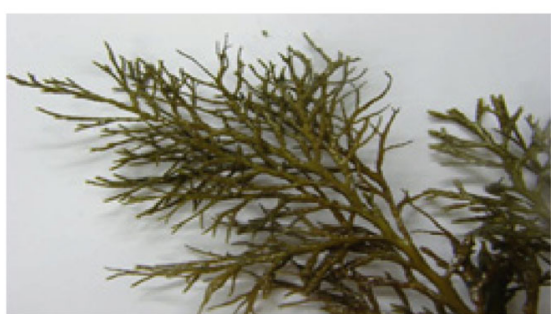

Fig. 2 a The first stage (bases) of Cystoceira compressa; b The second stage (young thalli) of Cystoseira compressa; and $\mathbf{c}$ The third stage of reproduction of Cystoseira compressa (adult thalli)

temperature (Del Vecchio et al. 1964; Nusca et al. 2008). For dissolved oxygen, the high concentrations recorded during the period of the study at site 3 could presumably be attributed to the photosynthetic activity of producing oxygen, which is favored by temperature. The direct effect of climate on water temperature, oxygen solubility and biomass metabolic activity is well established in the literature (Aminot and Chaussepied 1983).

The lowest values of dissolved oxygen were recorded on site 2 due to the high levels of pollution in the surrounding area, with asphyxiation waste and substances floating on the sea surface. Significant enrichment in phosphorus was observed for sites 1 and 2 , all samples showed levels of above $0.5 \mathrm{mg} \mathrm{L}^{-1}$, which was an indication of pollution. The low levels observed at site 3 can be explained by the assimilation of this element by phytoplankton. High levels of pollution have often been attributed to the discharge of wastewater from industrial areas, the bacterial activity on organic matter recycling, and the presence of large amounts of phosphorus in domestic waste waters (Lapucci and Pazienza 1966; Marini 1963). The values recorded for nitrites were lower than the high values observed for site 1 and site 2 . 


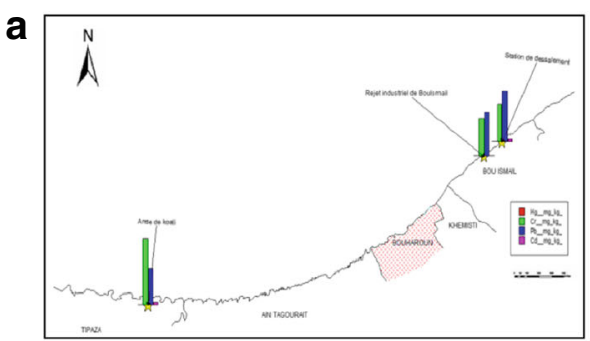

b

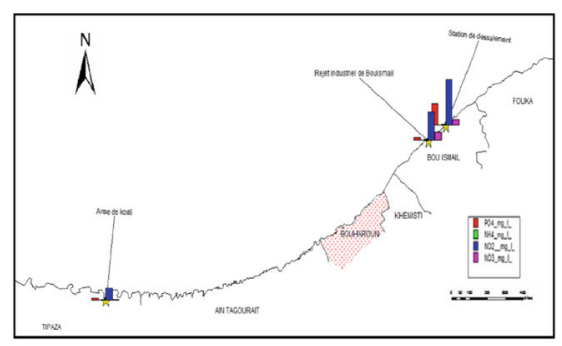

C

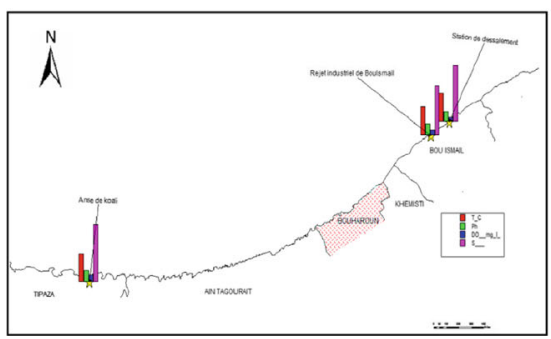

d

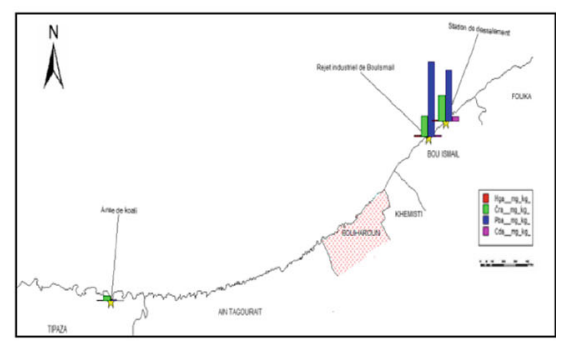

Fig. 3 a Spatial variation of physico-chemical parameters in the study area; $\mathbf{b}$ Spatial variation of nutrients in the study area; c Spatial distribution of heavy metals in the sediment; and d Spatial distribution of heavy metals in seaweed

This enrichment could be explained by the intensity of pollution in those two sites. Conversely, site 3 had lower values, which could be attributed to several factors as previously described elsewhere (Bethoux et al. 1999).

\subsection{Study of Heavy Metals in Sediment and Algae}

The changes recorded for trace metals $(\mathrm{Cd}, \mathrm{Pb}, \mathrm{Cr}$, and $\mathrm{Hg})$ in sediments are presented in Fig. 3c. The changes recorded for heavy metals $(\mathrm{Cd}, \mathrm{Pb}, \mathrm{Cr}$, and $\mathrm{Hg})$ in algae are illustrated in Figs. 3d and 4. Several algal species are widely used as bio-indicators of metal contamination in various parts of the world (Campanella et al. 2001). The results of the present study

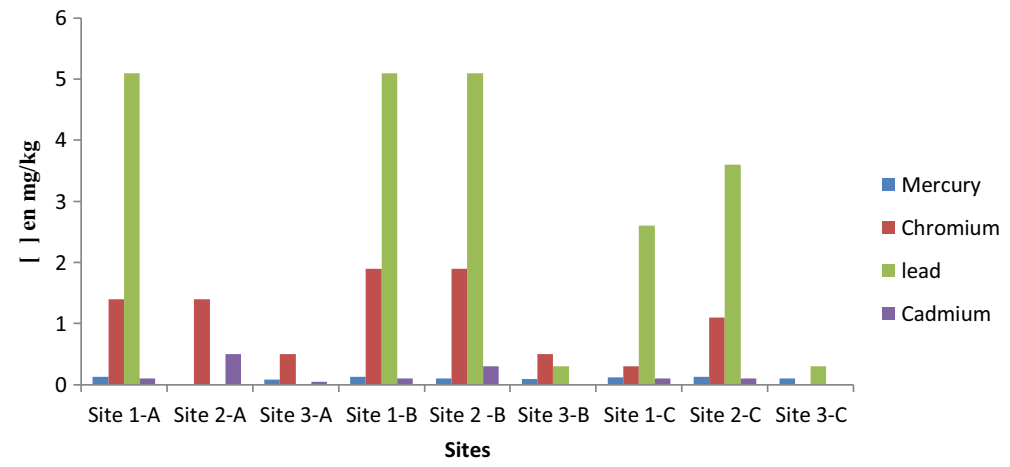

Fig. 4 Distribution of heavy metals in the seaweed (C. compressa). a sampling 1, b sampling 2, c sampling 3 
provided estimates on the range of lead and chromium values in the algae under investigation. The values recorded for lead in Cystoseira compressa taken from the uncontaminated site 3 ranged between 0 and $0.3 \mathrm{mg} \mathrm{kg}^{-1}$ dry weight, where as the lead values recorded at the heavily contaminated site 1 and site 2 varied between 2.6 and $5.1 \mathrm{mg} \mathrm{kg}^{-1}$ dry weight. These results on the levels of lead stored in Cystoseira compressa indicated that while cove Koali was only slightly contaminated by lead, sites 1 and 2 were heavily polluted by lead. The ranges of mean concentrations of chromium measured in Cystoseira compressa, from noncontaminated sites, were 0.1 to $0.5 \mathrm{mg} \mathrm{kg}^{-1}$ dry weight, and those from polluted sites ranged from 1.1 to $1.9 \mathrm{mg} \mathrm{kg}^{-1}$ dry weight. According to the data described in previous reports (Morgan et al. 2003; Shiber and Washburn 1979 ), particularly for the $\mathrm{Cd}, \mathrm{Cu}, \mathrm{Fe}$, $\mathrm{Mn}$ and $\mathrm{Zn}$ metal contents, and using these new values as a guide, it became clear that most stations in the city of Bou Ismail can be considered as having high levels of contamination and, hence, severe pollution by metal trace element (ETM). The significant levels of cadmium obtained in the algae collected could be attributed to the abundance of this metal in the industrial effluent emissions (Kaimoussi et al. 2002, 2004). Although the content of metals in algae was subject to large variations, a trend towards higher levels of mercury than other metals was observed along the coast of the town of Bou Ismaill, which is in agreement with previous studies using algae. While several studies reported on seasonal variations of heavy metals in algae, other studies reported on the absence of such variations (Benguedda et al. 2011). Among the studied species, Cystoseira compressa was noted to vary significantly during the period of sampling, with each species showing a specific metal variation model.

Comparisons of concentrations of metals in seaweed in the three sites by ANOVA test led to the following findings:

For mercury, ANOVA showed that calculated $\mathrm{F}(F=2.39)$ was less than the theoretical $\mathrm{F}$ $(F=7.26)$, which verifies the null hypothesis $(\mathrm{H} 0)$ at a $5 \%$ significance level, indicating that the general form of the spatial distribution of mercury concentrations is homogeneous in the three stations.

For chromium, the same procedure was followed for the comparison of concentrations of chromium in the three sites. The calculated $\mathrm{F}(F=3.83)$ was less than the critical $\mathrm{F}(F=7.26)$, so the null hypothesis was verified, and consequently, the difference between the average concentrations is not significant at the $5 \%$ level of significance. This result allowed us to say that chromium is distributed homogeneously in the three stations.

For lead, the ANOVA test showed that the calculated $\mathrm{F}(F=97.5)$ was much higher than the critical $\mathrm{F}(F=7.26)$ at $5 \%$ level of significance, so the null hypothesis was rejected. This means that the difference between the concentrations of lead in the three sites is significant and the distribution is heterogeneous.

For cadmium, the calculated $\mathrm{F}(F=2.36)$ was less than the critical $\mathrm{F}(F=7.26)$, so the null hypothesis was verified, and consequently, the difference between the average concentrations is not significant at the $5 \%$ level of significance. This allows us to say that the distribution of the cadmium in the three sites is homogeneous.

\subsection{Metal Interactions}

The speciation of a metal depends on other metals in the environment. In fact, these interaction shave significant, positive or negative, effects on the bioavailability of metals and, hence, on their bioaccumulation (Ahsanullah et al. 1981). The interactions and correlations between 
Table 1 Matrix of correlations between metals analyzed to the seaweed Cystoseira compressa

\begin{tabular}{lllll}
\hline & $\mathrm{Hg}$ & $\mathrm{Cr}$ & $\mathrm{Pb}$ & $\mathrm{Cd}$ \\
\hline $\mathrm{Hg}$ & 1.000 & & & \\
$\mathrm{Cr}$ & 0.299 & 1.000 & & \\
$\mathrm{~Pb}$ & -0.014 & 0.721 & 1.000 & 1.000 \\
$\mathrm{Cd}$ & 0.671 & 0.565 & 0.037 & \\
\hline
\end{tabular}

Values represent means of three independent replicates

metals were estimated using the Cystoseira compressa algae. The results on the correlation matrices are presented in Table 1 and reveal that the coefficients were significantly positive. A negatively correlation was observed between $\mathrm{Pb}$ and $\mathrm{Hg}$ (Table 1). The $\mathrm{Pb}$ showed, however, positive correlations with $\mathrm{Cd}$ and $\mathrm{Cr}$. The $\mathrm{Cr}$ and $\mathrm{Cd}$ often showed close geochemical behavior, which resulted from their common continental origin and explained their correlation. The $\mathrm{Cd}$ and $\mathrm{Hg}$ were also noted to have a good correlation (Ahsanullah et al. 1981). The results also showed correlated changes in the metal concentrations at the tissues of the brown seaweed. Parameters of water quality were examined using aggregate data on all the surveyed sites in an attempt to identify their potential influence on the metal charge.

The correlation results showed the presence of a relationship between the physico-chemical parameters and heavy metal contents. This allowed for the determination of the accumulation sensitivity to changing ecologic conditions. The results given in Table 2 illustrate the correlations between abiotic parameters and heavy metals.

Overall, the results indicated a number of important conclusions, namely that salinity was weakly correlated or negatively correlated with all metals, lead was correlated with $\mathrm{pH}$, and cadmium, chromium, and mercury were anti-correlated with $\mathrm{pH}$. The factors with the most important negative correlations in the case of dissolved oxygen were recorded for $\mathrm{Pb}, \mathrm{Cr}, \mathrm{Cd}$, $\mathrm{Hg}$, and the largest correlation coefficients were between phosphorus and nitrate with metals $\mathrm{Cr}$ and $\mathrm{Pb}$. The metals studied did not show any significant correlation with nitrite and ammonium.

Table 2 Matrix of correlations between metals in algae Cystoseira compressa and hydrological parameters of the medium

\begin{tabular}{lrrrr}
\hline & $\mathrm{Hg}$ & $\mathrm{Cr}$ & $\mathrm{Pb}$ & $\mathrm{Cd}$ \\
\hline $\mathrm{pH}$ & -0.396 & -0.182 & 0.297 & -0.666 \\
$\mathrm{Sal}$ & 0.485 & -0.606 & -0.375 & -0.306 \\
$\mathrm{OD}$ & -0.578 & -0.688 & -0.680 & -0.474 \\
Phosphorus & 0.093 & 0.443 & 0.458 & 0.207 \\
Nitrite & 0.419 & -0.111 & 0.130 & -0.021 \\
Nitrate & 0.256 & 0.787 & 0.779 & 0.200 \\
Ammonium & 0.117 & 0.064 & 0.128 & -0.093 \\
\hline
\end{tabular}

Values represent means of three independent replicates 


\section{Conclusions}

The results obtained in the study of bioaccumulation, and bio-monitoring of metals by the brown seaweed Cystoseira compressa led to the following conclusions: Cystoseira compressa is a heavy metal bioaccumulative and tolerant bioindicator of heavy metal pollution. The algae showed high levels of tolerance in increased ETM at the two sites (the desalination and industrial waste station) which were noted to be relatively polluted. The analysis of the sediments showed the presence of high heavy metal contents at sites 1 and 2. Overall, the accumulation in algae was more intense than in sediments.

Acknowledgments This work was funded by the Algerian Ministry of Higher Education and Scientific Research. The authors would like to express their gratitude to Mr. S. Kourdali and Mr. B. Zenati for their constructive discussions and valuable help during the preparation of this work. Special thanks are also due to Mr. A. Smaoui and Mrs. H. Ben Salem from the English department at the Sfax Faculty of Science (Sfax, Tunisia) for their constructive proofreading and language polishing services. The authors would also like to extend their thanks to the Editor and the anonymous reviewers for their valuable comments and efforts during the revision of the present manuscript.

\section{References}

Ahsanullah M, Negilski DS, Mobley MC (1981) Toxicity of zinc, cadmium and copper to the shrimp Callianassa australiensis. III. Accumulation of metals. Mar Biol 64:311-316

Alahverdi M, Savabieasfahani M (2012) Seaweed and chlorophyll as biomarkers of metals in the Persian Gulf, Iran. Bull Environ Contam Toxicol 89:501-506

Aminot A, Chaussepied M (1983) Manuel des analyses chimiques en milieu marin. CNEXO, Brest, p 395

Benguedda W, Dali Youcef N, Amara R (2011) Trace metals in sediments, macroalgae and benthic species from the western part of Algerian coast. J Environ Sci Eng 1604-1612

Bethoux JP, Gentili B, Morin P, Nicolas E, Pierre C, Ruiz-Pinoa D (1999) The Mediterranean Sea: a miniature ocean for climatic and environmental studies and a key for the climatic functioning of the North Atlantic. Prog Oceanogr 44:131-146

Boukhalfa C, Blake G, Mennour A (2006) Analysis and speciation of metals in sediments of an artificial water reserve in a mining zone the case of Guenitra Dam, Algeria. Environ Technol 27:885-890

Campanella L, Conti ME, Cubadda F, Sucapane C (2001) Trace metals in seagrass, algae and molluscs from an uncontaminated area in the Mediterranean. Environ Pollut 111:117-126

Del Vecchio V, Graziano F, D’Arca SU, Spalatin G, Vescia N (1964) The status of pollution of the Tiber in relation to its contaminants. 3. The water of Rome. Nuovi Ann Ig Microbiol 15(Suppl):717-744

Escuder-Gilabert L, Bonet-Domingo E, Medina-Hernandez MJ, Sagrado S (2007) A diagnostic tool for determining the quality of accuracy validation. Assessing the method for determination of nitrate in drinking water. Anal Bioanal Chem 387:619-625

Güner A, Köksal Ç, Erel ȘB, Kayalar H, Nalbantsoy A, Sukatar A, Karabay Yavaşoğlu NÜ (2015) Antimicrobial and antioxidant activities with acute toxicity, cytotoxicity and mutagenicity of Cystoseira compressa (Esper) Gerloff \& Nizamuddin from the coast of Urla (Izmir, Turkey). Cytotechnology 67:135-143. doi:10.1007/ s10616-013-9668-X

ISO:9174 (1998) Water quality determination of chromium AAS methods. p156

Kaimoussi A, Chafik A, Mouzdahir A, Bakkas S (2002) Diagnosis on the state of healthiness, quality of the coast and biological resources 'case of the Moroccan Atlantic coast' (City of El Jadida). C R Biol 325:253-260

Kaimoussi A, Mouzdahir A, Saih A (2004) Seasonal variations of metal contents (Cd, Cu, Fe, Mn and Zn) in seaweed Ulva lactuca from the coast of El Jadida city (Morocco). C R Biol 327:361-369

Lapucci PL, Pazienza A (1966) The importance of the determination in surface waters polluted with domestic waste waters, of the boron and phosphates contained in detergents. Riv Ital Ig 26:454-467

Marini V (1963) On a Pilot Plant for the treatment, in anaerobiosis, of domestic waste waters from small population groups. (First Series of Experiments). Riv Ital Ig 23:581-598 
Morgan JA, Aguiar AB, Fox S, Teichberg M, Valiela I (2003) Relative influence of grazing and nutrient supply on growth of the green macroalga Ulva lactuca in estuaries of Waquoit Bay, Massachusetts. Biol Bull 205: 252-253

Nusca A, D’Alessandro D, Funari E (2008) Indicators of water microbial pollution: problems and perspectives. Ann Ig 20:531-544

Reichelt-Brushett A (2012) Risk assessment and ecotoxicology: limitations and recommendations for ocean disposal of mine waste in the Coral Triangle. Oceanography 25:40-51

Rodier J (1996) L'analyse de l'eau. Eaux naturelles, eaux résiduaires, eau de mer, 8ème édition, Tomes I et II, Dunod. p1383

Schutze I, Muller W (1979) Determination of trace elements in dietary fats and emulsifiers by non-flame atomic absorption spectrometry (AAS). 2. Determination of mercury in dietary fats and emulsifiers. Nahrung 23: $867-874$

Shiber J, Washburn E (1979) Lead, mercury and certain nutrient elements in Ulva lactuca from Ras Beirut, Lebanon. Hydrobiologia 61:187-192

Singh P, Negi JS, Rawat MS, Joshi G (2012) Determination of trace elements in Rheum moorcroftianum by AAS. Nat Prod Res 26:161-166

Sondergaard J, Bach L, Gustavson K (2014) Measuring bioavailable metals using diffusive gradients in thin films (DGT) and transplanted seaweed (Fucus vesiculosus), blue mussels (Mytilus edulis) and sea snails (Littorina saxatilis) suspended from monitoring buoys near a former lead-zinc mine in West Greenland. Mar Pollut Bull 78:102-109 